\section{Cross-Canada colorectal}

\section{cancer screening programs}

\section{remain elusive}

$\mathrm{C}$

anadian provinces have made only minimal progress in introducing colorectal cancer screening programs, despite overwhelming evidence that aggressive screening and public education can help stem the progress of one of the most pervasive but preventable forms of cancer.

To date, only Ontario, Manitoba and Alberta have launched comprehensive programs. Most other provinces are either in the process of designing broad screening initiatives or studying the need for such a program.

The lack of progress deeply concerns colorectal cancer advocates, who continue to remind policy-makers that although it is the second leading cause of death from cancer in Canada, it is also among the most preventable (see page 545).

"We're still finding a lot of patients diagnosed with latter-stage [colorectal] cancer and that is really unacceptable," says Barry Stein, a Montréal lawyer, cancer survivor and president of the Colorectal Cancer Association of Canada. "A lot of provinces are studying the problem, but our experience is that just because a province says it's going to do screening, doesn't mean it's going to do it."

About 20 460 Canadians are diagnosed with colorectal cancer every year and 8700 die of it. Despite these starthing numbers and urgent recommendations from national roundtables dating back to the late I9gos, some provinces still haven't made any progress.

Stein says he believes some provinces are dragging their feet due to concerns about the increased cost of providing colonoscopies for those who test positive in screening tests. "They are not looking at the high cost of treatment and medication for those with late-stage cancer," he says. "All of those costs could be saved if we detected colorectal cancer before it becomes advanced."

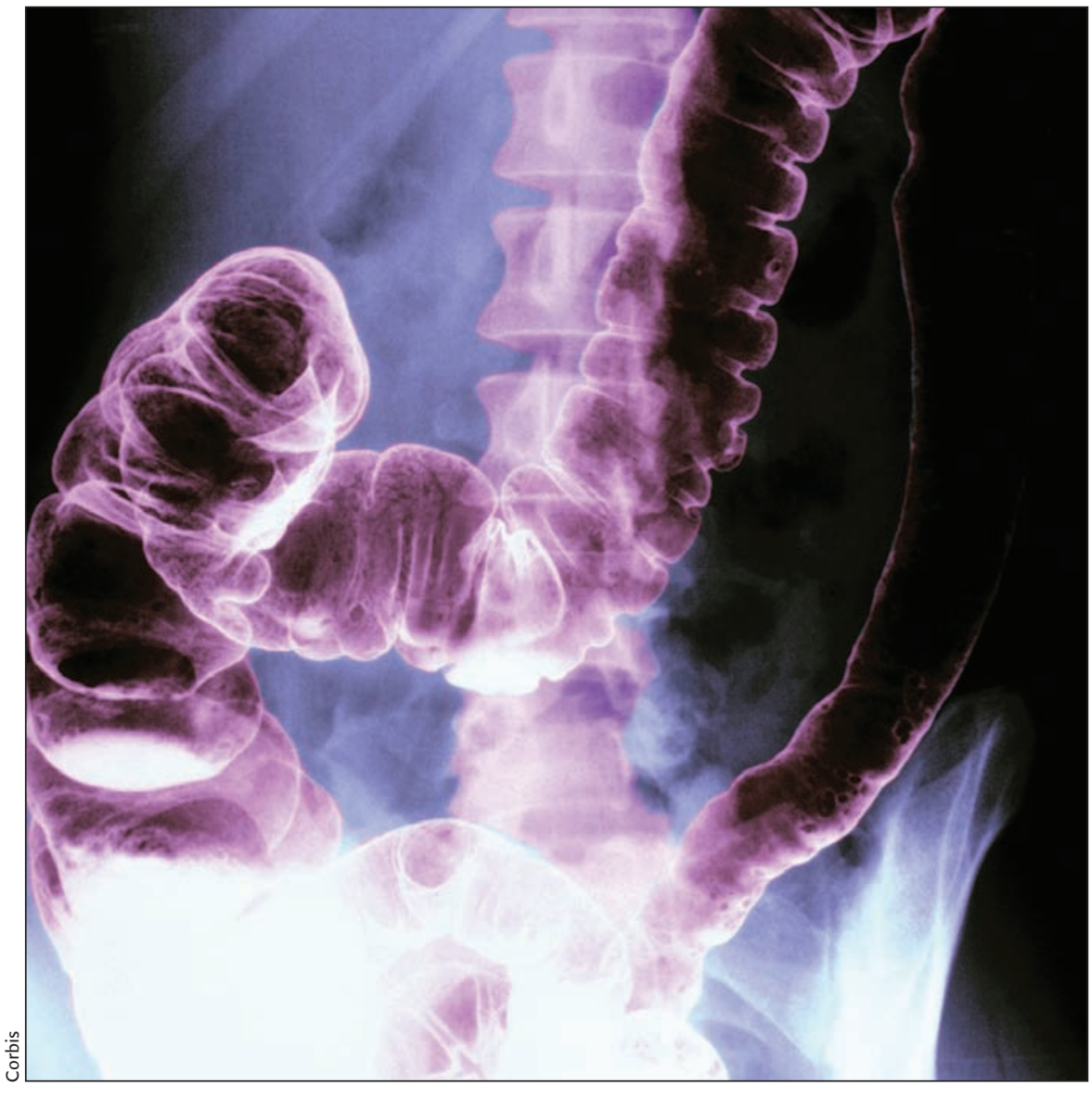

Colorectal cancer, the second leading cause of death from cancer in Canada, can be detected and treated early, but most provinces still don't have screening programs.

Ontario, Manitoba and Alberta introduced screening programs earlier this year.

The \$193-million Ontario program will be rolled out over 5 years. This year, there is funding for an additional 34000 colonoscopies for Ontarians with a family history of colorectal cancer and those who have a positive fecal occult blood test. In 2008 , fecal occult blood test kits will be available through all physician offices, group practices and clinics. As well, the kits will be available, free of charge, at pharmacies or by calling a toll-free line. Completed kits can be mailed free-ofcharge to designated laboratories.

Dr. Linda Rabeneck, regional vice president for Cancer Care Ontario, says the new screening program will be accompanied by an aggressive campaign to educate family physicians about the need to include fecal occult blood testing in primary care. Cancer Care Ontario reports that only $20 \%$ of Ontarians over age 50 receive any type of colorectal cancer screening.

Manitoba is proceeding with the first phase of a screening program that borrows heavily on methodology that has proven successful in the UK. This spring, Cancer Care Manitoba began placing fecal occult blood test kits in every physician's office and mailing out 20000 kits to eligible residents in the Winnipeg and Assiniboine Regional Health Authorities. Another 5000 kits will be distributed through the Manitoba Breast Screening Program.

Alberta is taking a research-based approach, with plans to roll out components over 5 years. "We don't want to overwhelm capacity by launching right 
away," says Dr. Huiming Yang, medical leader for the Alberta Colorectal Cancer Screening Program.

With funding from the $\$ 500$ million Alberta Cancer Prevention Legacy Fund, the program will begin with an intensive education campaign to encourage 50- to 74-year-olds at average risk to get screening. Future plans include developing clinical practice guidelines for physicians and distributing fecal occult blood test kits. "This will be a population based, sustainable program," says Yang.

Dr. Brent Schacter, former president of Cancer Care Manitoba (see page 556 ) and current president of the Canadian Association of Provincial Cancer Agencies, says other provinces are also considering screening programs, but they are complex, costly and involve large numbers of people. The movement to establish national breast cancer screening took almost ro years, he points out.

There is hope that screening programs could evolve more quickly with help from the Canadian Partnership Against Cancer, a national network of cancer specialists that provides expertise to provincial health ministries and cancer agencies, says Schacter.

"The concept behind populationbased screening is that you're pushing a test to well people," he says. "There are people of a certain age where the risks are very high. The bottom line is that you've got to be fairly open at the front end to make it easy for the patients to get involved." - Dan Lett, Winnipeg

DOI:I0.1503/cmaj.071127

\section{Cancer program puts family physicians at the frontline}

A unique Manitoba program is helping family physicians reclaim a primary role on the front line of cancer treatment.

The Urban Primary Care Oncology Network, thought to be the only program of its kind in Canada, is being hailed by Cancer Care Manitoba as the critical link between patients and the information they need about cancer screening, detection and treatment.

In place since 2004, the network links about 90 family physicians working in 15 group practices in Winnipeg and surrounding rural communities with Cancer Care Manitoba. The program provides those doctors with the latest information on cancer treatment, and counsels them on how to communicate with patients on all aspects of cancer diagnosis and treatment.

Dr. Jeff Sisler, director of primary care oncology for Cancer Care Manitoba, says the network is trying to keep the family physician as the primary source of information for all cancer patients. Many cancer patients suffer from a lack of information because either they don't have a regular family physician, or their doctors are not kept in the loop by cancer professionals, he says.

The network designates 1 physician at each group practice as the lead doctor for all cancer related issues, Sisler says. The other physicians use that lead doctor to get information about screening, detection and treatment whenever a patient has questions, he adds.

The group practice also gets access to a unique "electronic chart" that uses software developed at Cancer Care Manitoba to track every exam, doctor's note and treatment decision for all cancer patients in the province, he says.

Early results show that the network is succeeding in its primary goal of providing patients with more and better information about cancer, from initial screening to treatment, Sisler says. In addition, the program has been effective in helping cancer patients find full-time family doctors. At the onset of the network program, only $40 \%$ of Manitoba cancer patients had a regular family physician. The most recent data show that more than $80 \%$ of patients tracked by Cancer Care Manitoba now have a regular family doctor.

"What we're trying to do here is more global in its intent," Sisler says. "It's about relationship building, so patients, family docs and the cancer system are all in synch." - Dan Lett, Winnipeg

\section{New dosage limits for}

\section{medical marijuana:}

\section{But where's the science?}

$\mathrm{N}$ ew evidence-based guidelines are urgently needed to help doctors negotiate Canada's hazy medical marijuana landscape, particularly in light of Health Canada's efforts to impose new dose limits, say the nation's leading cannabis researcher and doctors who have been queried about their marijuana authorizations.

Canada should also re-establish a formal process for developing responsible dosing strategies, says Mark Ware of McGill's University Health Centre, the sole researcher funded under the now defunct Medical Marijuana Research Program (CMAJ 2006; 175:[12]: 1507-8).

The 1053 doctors now authorizing marijuana use for $18 \mathrm{r} 6$ patients need "more evidence" regarding rational dose levels, he says. And Ware suggests the Canadian Consortium for the Investigation of Cannabinoid could lead such an effort.

"There is more research, more trials, formulations that could be done," says Ware. "If we had a couple of days in a room with people and pharmacologists then we could sit around and say, here is the best we can come up with, here are some guidelines."

Under current medical marijuana rules, doctors authorize the amount of marijuana they and their patients feel is necessary. However, several who have recommended above $5 \mathrm{~g}$ per day were recently telephoned by a Health Canada medical marijuana program officer, and advised that the department recommends no more than $\mathrm{I}-3 \mathrm{~g}$ per day, irrespective of the medical condition or means of consumption (inhaled, ingested or both). Health Canada also posted that recommendation on its Web site in October 2006, after officials noted the number of authorized users prescribed at more than $5 \mathrm{~g}$ per day had increased to $15 \%$ in June, 2006 from Io\% a year earlier.

The lower $1-3$-g dose recommendation stems from "an examination of current available evidence on daily amounts," stated unnamed officials in 